\title{
Better performance on length-of-stay benchmarks associated with reduced risk following emergency department discharge: an observational cohort study
}

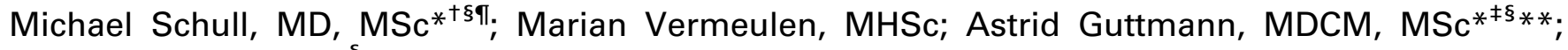 \\ Therese Stukel, $\mathrm{PhD}^{* \S}$
}

\section{ABSTRACT}

Introduction: Emergency department (ED) crowding is associated with adverse outcomes. Several jurisdictions have established benchmarks and targets for length-of-stay (LOS) to reduce crowding. An evaluation has been conducted on whether performance on Ontario's ED LOS benchmarks is associated with reduced risk of death or hospitalization.

Methods: A retrospective cohort study of discharged ED patients was conducted using population-based administrative data from Ontario (April 2008 to February 2012). For each ED visit, the proportion of patients seen during the same shift that met ED LOS benchmarks was determined. Performance was categorized as $<80 \%, 80 \%$ to $<90 \%, 90 \%$ to $<95 \%$, and 95\%-100\% of same-shift ED patients meeting the benchmark. Logistic regression models analysed the association between performance on ED LOS benchmarks and 7-day death or hospitalization, controlled for patient and ED characteristics and stratified by patient acuity.

Results: From 122 EDs, 2,295,256 high-acuity and 1,626,629 low-acuity visits resulting in discharge were included. Deaths and hospitalizations within 7 days totalled $1,429(0.062 \%)$ and $49,771(2.2 \%)$ among high-acuity, and $220(0.014 \%)$ and $9,005(0.55 \%)$ among low-acuity patients, respectively. Adverse outcomes generally increased among patients seen during shifts when a lower proportion of ED patients met ED LOS benchmarks. The adjusted odds ratios (and 95\% confidence intervals) among high- and low-acuity patients seen on shifts when $<80 \%$ met ED benchmarks (compared with $\geq 95 \%)$ were, respectively, $1.32(1.05-1.67)$ and 1.84 (1.21-2.81) for death, and $1.13(1.08-1.17)$ and $1.40(1.31-1.49)$ for hospitalization.

Conclusions: Better performance on Ontario's ED LOS benchmarks for each shift is associated with a $10 \%-45 \%$ relative reduction in the odds of death or admission 7 days after ED discharge.

\section{RÉSUMÉ}

Contexte: L'encombrement des services d'urgence (SU) est associé à des résultats défavorables. Des valeurs de référence et des cibles relatives à la durée de séjour (DS) ont été établies dans plusieurs provinces ou pays afin de réduire l'encombrement. L'étude visait donc à évaluer si le rendement fondé sur des valeurs de référence concernant la DS dans les $\mathrm{SU}$ en Ontario était associé à une réduction du risque de mortalité ou d'hospitalisation.

Méthode: Une étude rétrospective de cohortes composées de patients ayant quitté les SU a été menée à l'aide de données administratives fondées sur la population et recueillies en Ontario (avril 2008 à février 2012). Les auteurs ont déterminé, pour chacune des consultations au SU, la proportion de patients vus au cours d'une même période de travail qui respectait les valeurs de référence établies pour la DS dans les SU. Le degré de performance a été défini comme la proportion de patients vus au cours d'un même période de travail au SU ayant respecté les valeurs de référence, à hauteur de $<80 \%$, de 80 à $<90 \%$, de 90 à $<95 \%$ et de 95 à $100 \%$. Des modèles de régression logistique ont permis d'analyser l'association entre le rendement fondé sur des valeurs de référence concernant la DS dans les SU et la mortalité ou I'hospitalisation au bout de 7 jours, de garder fixes les caractéristiques des patients et des $\mathrm{SU}$ et de diviser les patients selon leur état de gravité.

Résultats: L'étude comptait 2295256 consultations pour des états graves et 1626629 consultations pour des états non graves, données dans $122 \mathrm{SU}$, qui se sont soldées par le renvoi des patients. Le nombre de décès et d'hospitalisations au bout de 7 jours atteignait respectivement $1429(0,062 \%)$ et $49771(2,2 \%)$ parmi les cas graves, et $220(0,014 \%)$ et 9005 $(0,55 \%)$ parmi les cas peu graves. Une augmentation générale des résultats défavorables a été notée au cours des périodes de travail durant lesquelles une faible proportion de patients vus au SU respectait les valeurs de référence établies pour la

From the *Institute for Clinical Evaluative Sciences, University of Toronto, ON; †Department of Medicine, University of Toronto, ON; $\neq D e p a r t m e n t$ of Pediatrics, University of Toronto, ON; §Institute for Health Policy, Management and Evaluation, University of Toronto, ON; $\uparrow$ Sunnybrook Health Sciences Centre, Toronto, ON; and ${ }^{* *}$ The Hospital for Sick Children, Toronto, ON.

Correspondence to: Marian Vermeulen, Institute for Clinical Evaluative Sciences, 2075 Bayview Avenue, Toronto, ON M4N 3M5; marian.vermeulen@ices.on.ca 
DS dans les SU. Les risques relatifs approchés, rajustés (intervalle de confiance à $95 \%$ ) chez les patients qui étaient dans un état grave et chez ceux qui ne l'étaient pas, vus au cours de périodes de travail durant lesquelles $<80 \%$ des valeurs de référence fixées dans les SU (comparativement à un taux de $\geq 95 \%$ ) étaient respectées se sont établis respectivement à $1,32(1,05-1,67)$ et à $1,84(1,21-2,81)$ en ce qui concerne la mortalité et à $1,13(1,08-1,17)$ et à 1,40 $(1,31-1,49)$ en ce qui concerne l'hospitalisation.
Conclusion: Une augmentation du rendement fondé sur des valeurs de référence concernant la DS dans les SU en Ontario pour chaque période de travail est associée à une réduction relative du risque de mortalité ou d'hospitalisation de l'ordre de 10 à $45 \%$ au bout de 7 jours après le congé du SU.

Keywords: Emergency Department, Waiting Times,

Performance Targets, Outcomes

\section{INTRODUCTION}

Long waits for care in crowded emergency departments (ED) occur in the United States, Canada, Australia, the UK, and many other developed countries. Numerous studies have demonstrated adverse effects of ED crowding, both on processes of care ${ }^{1-4}$ and on important patient outcomes, including mortality. ${ }^{5-9}$ One policy approach, which has been undertaken in several countries and several Canadian provinces, is to establish benchmarks for maximum ED length of stay (LOS), commonly known as ED LOS benchmarks. ${ }^{10,11}$ Recently, the Canadian Association of Emergency Physicians released a position statement recommending national benchmarks for ED performance with respect to ED LOS. ${ }^{12}$

ED LOS benchmarks encourage hospitals to focus on improving patient flow but are controversial. Several jurisdictions that have adopted them have seen substantial improvements in ED patients meeting targets. ${ }^{13-16}$ However, such initiatives may result in unintended adverse consequences by encouraging rushing of patient care or gaming of data. ${ }^{13,17}$ The selection of ED LOS benchmark thresholds has been arbitrary rather than evidence-based, ${ }^{18}$ and empiric data linking performance on benchmarks with patient outcomes has been lacking.

In April 2008, Ontario established and began publicly reporting provincial benchmarks for all EDs, specifically the maximum time that patients should spend in the ED from arrival to physical departure and the target percentage for compliance with the benchmark. Hospitals worked to achieve these targets, ${ }^{14}$ aided by Ministry-of-Health-funded initiatives, including a hospital pay-for-performance program, clinical observation units, and external quality improvement coaching advice. ${ }^{14,19}$ The objective was to determine whether better performance with respect to Ontario's ED LOS benchmarks was associated with improved patient outcomes. It was hypothesized that patients seen on shifts during which a lower proportion of patients meet Ontario ED LOS benchmarks are at higher risk of death or hospitalization within 7 days of ED discharge.

\section{METHODS}

\section{Setting and participants}

A retrospective cohort study of ED visits was conducted over 4 years from April 1, 2008, to February 28, 2012, in Ontario (population, 12 million). All Ontario EDs use a validated five-level triage tool, the Canadian Triage and Acuity Scale (CTAS), with common training programs for triage nurses. ${ }^{20}$ Ontario's ED LOS benchmarks are $<4$ hours for all non-admitted lowacuity patients (CTAS 4 or 5 ), and $<8$ hours for all high-acuity (CTAS 1, 2, or 3) or admitted patients. We excluded EDs with a mean annual patient volume below the 25 th percentile $(<13,647)$ because wait times are usually not prolonged at such sites, and they tend to have a different case mix and lower admission rates and acuity levels. ${ }^{5,21}$ The study population comprised patients who were seen by a physician and discharged from the ED. Patients who left without seeing a physician or left after seeing a physician either without treatment or against medical advice were excluded. When patients had more than one visit during the study period, the earliest visit was selected.

\section{Study exposures}

For each ED visit, the main exposure was calculated as the percentage of all similar patients registered in the same ED during the same shift who met their respective Ontario ED wait time benchmark. Similar patients were defined as those with the same triage score, grouped as 
high acuity (CTAS 1-3 [resuscitation, emergent, and urgent]) or low acuity (CTAS 4-5 [less urgent and nonurgent]). Patients for whom the ED LOS benchmark could not be calculated were excluded. The percentage of patients meeting the benchmarks on a given shift was calculated based on ED LOS and measured from the time of triage or registration (whichever came first) to the time that the patient left the ED or, if the latter was missing, to final patient disposition. Although the study population comprised discharged patients only, admitted patients were included in the calculation of the main exposure because they are known to substantially contribute to ED crowding. Those who left without being seen were excluded because their departure times are usually unknown. Shifts were defined in 8-hour increments starting at 0800, 1600, and 2400. The percentage of patients meeting ED LOS benchmarks was grouped as $<80 \%, 80 \%$ to $<90 \%$, $90 \%$ to $<95 \%$, and $95 \%-100 \%$ (the reference group). These groups were chosen because they encompassed common thresholds set for ED LOS benchmarks of $80 \%,{ }^{12} 90 \%,{ }^{12,22}$ and $95 \%{ }^{23}$ in several jurisdictions and allowed comparison effects at lower thresholds.

\section{Main outcome measures}

ED visit records were linked to outpatient and subsequent ED visits, hospital admissions, and death in the 7 days following the index ED visit. Adverse events were defined as death or a hospital admission within 7 days after leaving the ED. This time frame was chosen to ensure that subsequent events were related to the index ED visit. Unplanned returns within 7 days represent an important quality-of-care measure. ${ }^{24}$ More than $80 \%$ of adverse events following ED discharge occur within the first 10 days. $^{25}$ As a sensitivity analysis, outcomes at 30 days following the index ED visit were also examined.

\section{Data sources}

Patient records were linked using unique, anonymized, encrypted identifiers across multiple Ontario population-based health administrative databases containing information on all publicly insured hospital and physician services. ED visits were identified through the National Ambulatory Care Reporting System. ${ }^{26-28}$ Hospitalizations were identified through the Discharge Abstract Database. ${ }^{29}$ Deaths were determined from an enhanced population-based registry of all legal residents in Ontario. ${ }^{30}$ The Ontario Ministry of Health mandates submission of data on all ED visits and hospital separations in the province. ${ }^{31,32}$ The anonymous and unique identifier can link across databases to identify all patient admissions and deaths, including those that occurred in settings outside of the index visit institution. Neighborhood income and community type were obtained from Statistics Canada 2006 census estimates. These datasets were linked using unique, encoded identifiers and analyzed at the Institute for Clinical Evaluative Sciences (ICES).

\section{Statistical analyses}

Conditional logistic regression models were used, conditioning on ED as a fixed effect, to analyse the association between the percentage of patients meeting the benchmark and adverse events. ${ }^{5}$ This allowed for assessing the effects of increases or decreases in the percentage meeting benchmark during shifts within the same ED, while controlling for other factors. ${ }^{33}$ All models included the percentage of patients meeting ED LOS benchmarks and used a patient visit as the unit of analysis, permitting the ability to control for individual risk factors and inferences to individual patient outcomes, even for exposures measured at the ED level. Models were controlled for patient age group $(0-1,1-9,10-17,18-39,40-$ $64,65-74,75+$ years), sex, acuity, calendar month, fiscal year, weekend/holiday versus weekday, time of day (0801-1600, 1601-2400, 2401-0800), patient neighbourhood income quintile (including missing), patient neighbourhood community type (rural, urban, missing), hospital type (small, community, teaching), number of ED visits in the past year, and chief complaint. All analyses were stratified by CTAS category (1-3 [high acuity] and 4-5 [low acuity]). Patients with missing data on CTAS were excluded. A $p$-value less than or equal to 0.05 was deemed statistically significant, and all statistical tests were two sided. The patient's own LOS was not included as a separate variable in the models as shift characteristics were investigated. It was included in the shift-level calculation of the percentage of patients meeting ED LOS benchmarks. All analyses were performed using SAS for UNIX, Version 9.2.1 (SAS Institute, Cary, NC). Conditional logistic models used the procedure PROC LOGISTIC with a STRATA statement and included fixed effects for each ED.

The Research Ethics Board of Sunnybrook Health Sciences Centre approved this study. 


\section{RESULTS}

There were 4,792,669 visits during the study period, of which 4,092,399 were among patients who were discharged; 157,403 visits were excluded to low volume EDs, including 10,951 visits where the ED LOS benchmark could not be calculated, leaving 3,924,045 visits at $122 \mathrm{EDs}$. Of these, 3,921,885 had a valid CTAS value; $58.5 \%$ were high acuity (CTAS 1,2 , or 3 ), and $41.5 \%$ were low acuity (CTAS 4 or 5 ).

In terms of ED level performance with respect to ED LOS benchmarks at the time that the patients were seen in the ED, $37.1 \%$ of patients were seen during shifts where fewer than $80 \%$ of patients met the benchmark, $28.0 \%$ during shifts where $80 \%$ to $<90 \%$ met the benchmark, $13.4 \%$ during shifts where $90 \%$ to $<95 \%$ met the benchmark, and $21.5 \%$ during shifts where $95 \%$ or more met the benchmark (Table 1). There was substantial variation among EDs in the overall proportion of patients who met the Ontario ED LOS benchmark during the study period (range of $7.9 \%$ to $87.5 \%$ ). ED visits that occurred during shifts characterized by poor performance (i.e., where less than $80 \%$ of ED patients met the benchmark) were more likely to have been made by patients who were urban residents, older, had a higher acuity and lower income, and visits were more likely to have occurred at night and on weekdays, and more likely to have been at teaching or high-volume EDs.

Among high- and low-acuity patients, respectively, there were $1,429(0.062 \%)$ and $220(0.014 \%)$ deaths and 49,771 (2.2\%) and 9,005 (0.55\%) admissions within 7 days of ED discharge. Crude rates of death and admission were highest among patients attending the ED during shifts where fewer than $80 \%$ of patients met the ED LOS benchmark, regardless of acuity, and rates generally decreased as the percentage of patients meeting the benchmark increased (Table 2).

In adjusted analyses, patients seen during a shift characterized by a worse ED LOS benchmark performance were at significantly increased odds of both death and hospital admission (Figure 1a and Figure 1b). The odds of admission increased steadily as the shiftlevel performance with respect to ED LOS benchmarks worsened. A similar trend was seen for deaths with the exception of high-acuity patients, where a nonsignificant increase was observed in mortality associated with shifts where $80 \%$ to $<90 \%$ of patients met the benchmarks. Among high-acuity ED patients, the adjusted odds of death and hospitalization following discharge when seen during a poor performance shift (i.e., where $<80 \%$ of patients meet benchmarks) were 1.32 (95\% confidence interval [CI]: 1.05-1.67) and 1.13 (95\% CI: 1.08-1.17), respectively, compared with being seen during a high performance shift (i.e., where $95 \%-$ $100 \%$ of patients meet benchmarks). For low-acuity patients, being seen during a poor performance shift had an adjusted odds ratio of death and hospitalization of 1.84 (95\% CI: $1.21-2.81$ ) and 1.40 (95\% CI: $1.31-$ 1.49), respectively, compared with being seen during a high performance shift. In the sensitivity analysis examining 30-day outcomes, the adjusted odds ratios were very similar to those for the 7-day outcomes.

\section{DISCUSSION}

Prior studies have found adverse consequences associated with ED crowding, including treatment delays, ${ }^{1-4}$ hospitalization, ${ }^{5}$ and mortality. ${ }^{5-9}$ The recent relaxation of ED LOS benchmarks from $98 \%$ to $95 \%$ in the UK has resulted in substantially more patients waiting longer than 4 hours, and it has been suggested that this is likely to result in poorer patient outcomes. ${ }^{23}$ The implementation of ED LOS benchmarks and targets is based on the theory that reducing ED LOS enough to achieve a given benchmark for a sufficient proportion of patients will result in meaningful reductions in risk to patients, yet to date there has been no empiric evidence supporting any specific benchmarks. The results of this study suggest that not only are Ontario's ED LOS benchmarks an appropriate metric for quality improvement, but also that performance on a given shift is important. The results also demonstrate substantial additional room for improvement in performance, considering approximately $56 \%$ of patient visits occurred during shifts where $<90 \%$ of similar patients were meeting Ontario's benchmarks. In addition, the data suggest that achieving higher performance targets confers additional benefit. Ontario's target for compliance with its benchmarks is $\geq 90 \%$, yet even greater benefits were observed for patients when $\geq 95 \%$ compliance with benchmarks was achieved.

Poor performance on ED LOS benchmarks may result in adverse consequences for patients through a number of potential mechanisms. Prolonged ED LOS can lead to delays in diagnosis and/or treatment for specific conditions, such as timely administration of 


\begin{tabular}{|c|c|c|c|c|}
\hline \multirow[b]{2}{*}{ Patient/ED characteristic } & \multicolumn{4}{|c|}{$\begin{array}{l}\text { ED length-of-stay performance for all patients seen during the same shift* (\% of patients } \\
\text { meeting Ontario benchmarks }{ }^{\dagger} \text { ) }\end{array}$} \\
\hline & $\begin{array}{l}\text { Less than } 80 \% \\
N=1,468,647\end{array}$ & $\begin{array}{l}80 \% \text { to }<90 \% \\
N=1,110,897\end{array}$ & $\begin{array}{l}90 \% \text { to }<95 \% \\
N=531,660\end{array}$ & $\begin{array}{c}95 \%+ \\
N=861,621\end{array}$ \\
\hline \multicolumn{5}{|l|}{ Age group (years) } \\
\hline$<1$ & $136,388(9.3)$ & $125,934(11.3)$ & $67,506(12.7)$ & $108,168(12.6)$ \\
\hline $1-9$ & $123,789(8.4)$ & $109,354(9.8)$ & $63,525(12.0)$ & $111,532(12.9)$ \\
\hline $10-17$ & $449,693(30.6)$ & $319,366(28.8)$ & $146,394(27.5)$ & $232,824(27.0)$ \\
\hline $18-39$ & $483,472(32.9)$ & $351,494(31.6)$ & $162,653(30.6)$ & $268,327(31.1)$ \\
\hline $40-64$ & $118,432(8.1)$ & $83,735(7.5)$ & $37,281(7.0)$ & $60,261(7.0)$ \\
\hline $65-75$ & $102,915(7.0)$ & $68,498(6.2)$ & $28,034(5.3)$ & $38,418(4.5)$ \\
\hline$>75$ & $53,958(3.7)$ & $52,516(4.7)$ & $26,267(4.9)$ & $42,091(4.9)$ \\
\hline \multicolumn{5}{|l|}{ Sex } \\
\hline Female & $756,444(51.5)$ & $566,607(51.0)$ & $265,515(49.9)$ & $421,119(48.9)$ \\
\hline Male & $712,186(48.5)$ & $544,281(49.0)$ & $266,138(50.1)$ & $440,489(51.1)$ \\
\hline \multicolumn{5}{|l|}{ CTAS category (score) } \\
\hline Resuscitation (1) & $3,400(0.23)$ & $2,240(0.20)$ & $821(0.15)$ & $649(0.08)$ \\
\hline Emergent (2) & $251,164(17.1)$ & $185,219(16.7)$ & $60,825(11.4)$ & $49,770(5.8)$ \\
\hline Urgent (3) & 723,827 (49.3) & $589,811(53.1)$ & 217,217 (40.9) & $235,517(27.3)$ \\
\hline Less-Urgent (4) & $450,593(30.7)$ & $306,151(27.6)$ & $230,942(43.4)$ & $516,768(60.0)$ \\
\hline Non-urgent (5) & $39,070(2.7)$ & $27,122(2.4)$ & $21,625(4.1)$ & $57,875(6.7)$ \\
\hline Missing & $593(0.04)$ & $354(0.03)$ & $230(0.04)$ & $1,042(0.12)$ \\
\hline \multicolumn{5}{|l|}{ Neighbourhood income quintile (Q) } \\
\hline Q1 (lowest) & $314,674(21.4)$ & 215,362 (19.386) & $94,823(17.835)$ & $149,263(17.324)$ \\
\hline Q2 & $301,016(20.5)$ & $215,423(19.392)$ & $100,172(18.841)$ & $162,743(18.888)$ \\
\hline Q3 & $287,218(19.6)$ & $220,768(19.873)$ & $107,743(20.265)$ & 178,172 (20.679) \\
\hline Q4 & $284,041(19.3)$ & $235,994(21.244)$ & $117,761(22.150)$ & $191,921(22.274)$ \\
\hline Q5 (highest) & $275,361(18.8)$ & $218,184(19.640)$ & $108,302(20.371)$ & $174,138(20.211)$ \\
\hline Missing & $6,337(0.43)$ & $5,166(0.47)$ & $2,859(0.538)$ & $5,384(0.625)$ \\
\hline \multicolumn{5}{|l|}{ Community type } \\
\hline Urban & $1,386,828(94.4)$ & $1,025,295(92.3)$ & $459,963(86.5)$ & $612,541(71.1)$ \\
\hline Rural & $79,731(5.4)$ & $83,967(7.6)$ & $70,873(13.3)$ & $247,672(28.8)$ \\
\hline Missing & $2,088(0.14)$ & $1,635(0.15)$ & $824(0.16)$ & $1,408(0.16)$ \\
\hline \multicolumn{5}{|l|}{ Time of day (shift) } \\
\hline Day (8 am to 4 pm) & $647,275(44.1)$ & $516,255(46.5)$ & $257,688(48.5)$ & $386,828(44.9)$ \\
\hline Evening ( $4 \mathrm{pm}$ to midnight) & $569,845(38.8)$ & $459,056(41.3)$ & $229,800(43.2)$ & 360,902 (41.9) \\
\hline Night (Midnight to 8 am) & $251,527(17.1)$ & $135,586(12.2)$ & $44,172(8.3)$ & $113,891(13.2)$ \\
\hline \multicolumn{5}{|l|}{ Day of week } \\
\hline Weekday & $1,105,812(75.3)$ & $764,374(68.8)$ & $349,005(65.6)$ & $564,660(65.5)$ \\
\hline Weekend/holiday & $362,835(24.7)$ & $346,523(31.2)$ & $182,655(34.4)$ & $296,961(34.5)$ \\
\hline \multicolumn{5}{|l|}{ Number of ED visits in the prior year } \\
\hline 0 & $886,104(60.3)$ & $660,243(59.4)$ & $311,436(58.6)$ & $478,764(55.6)$ \\
\hline 1 & $292,816(19.9)$ & $224,271(20.2)$ & $106,260(20.0)$ & $172,133(20.0)$ \\
\hline 2 & $34,831(2.4)$ & $26,101(2.4)$ & $13,542(2.6)$ & $24,595(2.9)$ \\
\hline $3+$ & $254,896(17.4)$ & $200,282(18.0)$ & $100,422(18.9)$ & $186,129(21.6)$ \\
\hline \multicolumn{5}{|l|}{ Main problem at index ED visit } \\
\hline Injury/trauma/MSK & $552,865(37.7)$ & $430,946(38.8)$ & $232,874(43.8)$ & $388,587(45.1)$ \\
\hline Mental health & $37,432(2.6)$ & $25,475(2.3)$ & $9,179(1.7)$ & $10,927(1.3)$ \\
\hline Gastrointestinal & $94,905(6.5)$ & $66,367(6.0)$ & $24,218(4.6)$ & $27,889(3.2)$ \\
\hline Chest pain & 77,609 (5.3) & $52,842(4.8)$ & $17,690(3.3)$ & $17,323(2.0)$ \\
\hline Shortness of breath/Asthma & $19,120(1.3)$ & $14,415(1.3)$ & $5,983(1.1)$ & $8,129(0.94)$ \\
\hline Upper respiratory tract infection/otitis media & $74,280(5.1)$ & $66,734(6.0)$ & $39,165(7.4)$ & $87,813(10.2)$ \\
\hline
\end{tabular}




\begin{tabular}{|c|c|c|c|c|}
\hline \multirow[b]{2}{*}{ Patient/ED characteristic } & \multicolumn{4}{|c|}{$\begin{array}{l}\text { ED length-of-stay performance for all patients seen during the same shift* (\% of patients } \\
\text { meeting Ontario benchmarks }{ }^{\dagger} \text { ) }\end{array}$} \\
\hline & $\begin{array}{l}\text { Less than } 80 \% \\
\mathrm{~N}=1,468,647\end{array}$ & $\begin{array}{l}80 \% \text { to }<90 \% \\
N=1,110,897\end{array}$ & $\begin{array}{c}90 \% \text { to }<95 \% \\
N=531,660\end{array}$ & $\begin{array}{c}95 \%+ \\
N=861,621\end{array}$ \\
\hline Fever & $11,952(0.81)$ & $10,021(0.90)$ & $4,048(0.76)$ & 4,898 (0.57) \\
\hline Headache/neurological & $91,208(6.2)$ & $63,533(5.7)$ & $22,406(4.2)$ & $24,382(2.8)$ \\
\hline Skin & $53,951(3.7)$ & $43,164(3.9)$ & $24,839(4.7)$ & $50,298(5.8)$ \\
\hline Genitourinaryobstetric & $116,377(7.9)$ & $80,632(7.3)$ & $32,521(6.1)$ & $45,263(5.3)$ \\
\hline Administrative issue & $25,467(1.7)$ & $20,072(1.8)$ & $11,499(2.2)$ & $23,329(2.7)$ \\
\hline General signs and symptoms & $47,327(3.2)$ & $34,772(3.1)$ & $13,859(2.6)$ & $18,992(2.2)$ \\
\hline Other & $266,154(18.1)$ & $201,924(18.2)$ & $93,379(17.6)$ & $153,791(17.9)$ \\
\hline \multicolumn{5}{|l|}{ Hospital type } \\
\hline Small & $18,771(1.3)$ & $22,517(2.0)$ & $25,792(4.9)$ & $141,620(16.4)$ \\
\hline Community & $1,036,149(70.6)$ & $907,194(81.7)$ & $443,770(83.5)$ & $648,171(75.2)$ \\
\hline Teaching & $413,727(28.2)$ & $181,186(16.3)$ & $62,098(11.7)$ & $71,830(8.3)$ \\
\hline \multicolumn{5}{|l|}{ Average annual ED volume } \\
\hline $13,760-<26,000$ & $60,097(4.1)$ & $66,194(6.0)$ & $65,815(12.4)$ & 291,815 (33.9) \\
\hline $26,000-<45,000$ & $307,525(20.9)$ & 220,437 (19.8) & $138,299(26.0)$ & 269,383 (31.3) \\
\hline $45,000-100,816$ & $1,101,025(75.0)$ & $824,266(74.2)$ & $327,546(61.6)$ & 300,423 (34.9) \\
\hline
\end{tabular}

\section{Table 2. Outcomes among study patients* by patient acuity and shift level ED length-of-stay (ED-LOS) performance}

\begin{tabular}{|c|c|c|c|c|c|c|}
\hline \multirow{2}{*}{$\begin{array}{l}\text { ED LOS performance for } \\
\text { all patients seen during } \\
\text { the same shift ( } \% \text { of } \\
\text { patients meeting } \\
\text { Ontario benchmarks }{ }^{\dagger} \text { ) }\end{array}$} & \multicolumn{3}{|c|}{$\begin{array}{l}\text { High Acuity (Canadian Triage and Acuity } \\
\qquad \text { Scale 1-3) }\end{array}$} & \multicolumn{3}{|c|}{$\begin{array}{l}\text { Low Acuity (Canadian Triage and Acuity } \\
\qquad \text { Scale 4-5) }\end{array}$} \\
\hline & $\begin{array}{l}\text { Number of ED } \\
\text { visits (\%) }\end{array}$ & $\%$ Died & $\%$ Hospitalized & $\begin{array}{l}\text { Number of ED } \\
\text { visits (\%) }\end{array}$ & $\%$ Died & $\%$ Hospitalized \\
\hline $95 \%$ to $100 \%$ & $285,936(12.2)$ & $0.054(0.046,0.063)$ & $2.12(2.06,2.17)$ & 574,643 (34.6) & $0.009(0.007,0.012)$ & $0.44(0.42,0.46)$ \\
\hline $90 \%$ to $<95 \%$ & $278,863(12.0)$ & $0.066(0.057,0.076)$ & $2.07(2.02,2.12)$ & 252,567 (15.3) & $0.011(0.007,0.016)$ & $0.51(0.48,0.54)$ \\
\hline $80 \%$ to $<90 \%$ & $777,270(33.5)$ & $0.055(0.050,0.060)$ & $2.10(2.06,2.13)$ & $333,273(20.3)$ & $0.018(0.014,0.023)$ & $0.59(0.57,0.62)$ \\
\hline Less than $80 \%$ & 978,391 (42.3) & $0.071(0.066,0.076)$ & $2.28(2.25,2.31)$ & 489,663 (29.8) & $0.017(0.014,0.022)$ & $0.70(0.67,0.72)$ \\
\hline
\end{tabular}

antibiotics for pneumonia ${ }^{1,34}$ and febrile neonates, ${ }^{35}$ reperfusion for acute myocardial infarction patients, ${ }^{2,34}$ orders and completion of computed tomography scans for stroke, $^{36}$ medication orders for asthma, ${ }^{37}$ and administration of analgesics for hip fracture and other painful conditions. ${ }^{3,4,38,39}$ Crowding in the ED may also affect disposition decisions and has been associated with a lower likelihood of hospital admission in a study of pediatric ED patients with asthma or gastroenteritis. ${ }^{40}$ The current study adds to this prior work by demonstrating an association with serious adverse events when ED crowding is expressed as shift-level performance on Ontario's ED LOS benchmarks. Furthermore, this study's sensitivity analysis demonstrates persistence of the increased risk to 30 days post-ED discharge.

The selection of benchmarks and performance targets has been driven by a combination of expert opinion, local clinical practice, and political acceptability, all in the absence of evidence to guide decisions. Internationally, several jurisdictions, such as England, ${ }^{15}$ 

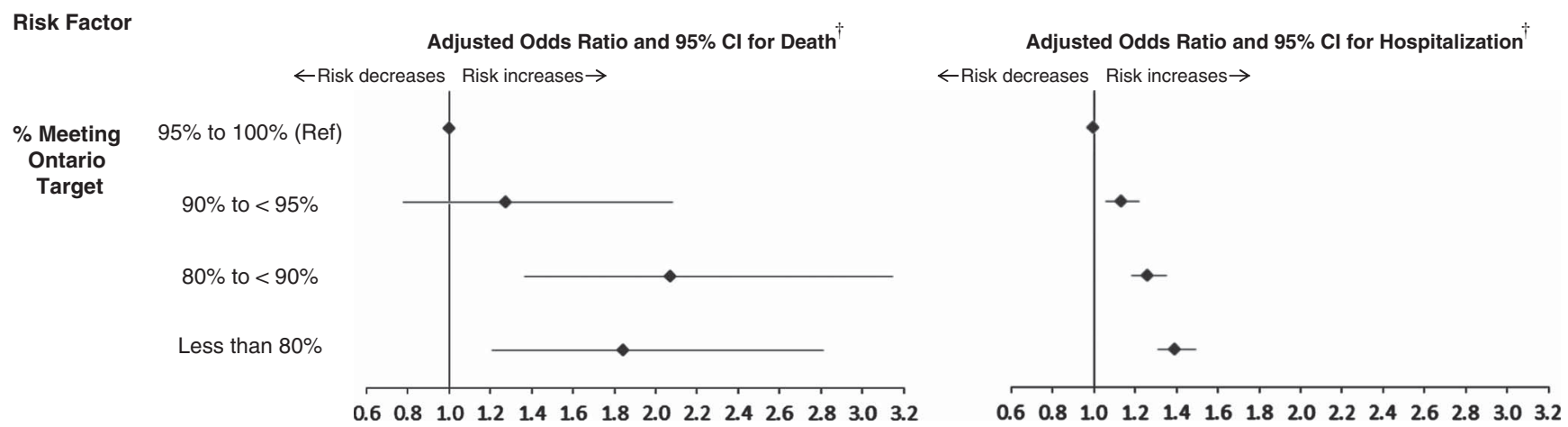

Figure 1a. High acuity* patients' emergency department patients' adjusted odds ratios (95\% confidence intervals) for death and hospitalization within 7 days of a visit among all non-admitted patients (seen-and-discharged and left-without-being-seen). *Canadian Triage and Acuity Scale levels 1 to 3.

tadjusted for age group, sex, triage level, calendar month, time of day, day of week, income quintile, urban/rural community, number of ED visits in the previous year, main problem.
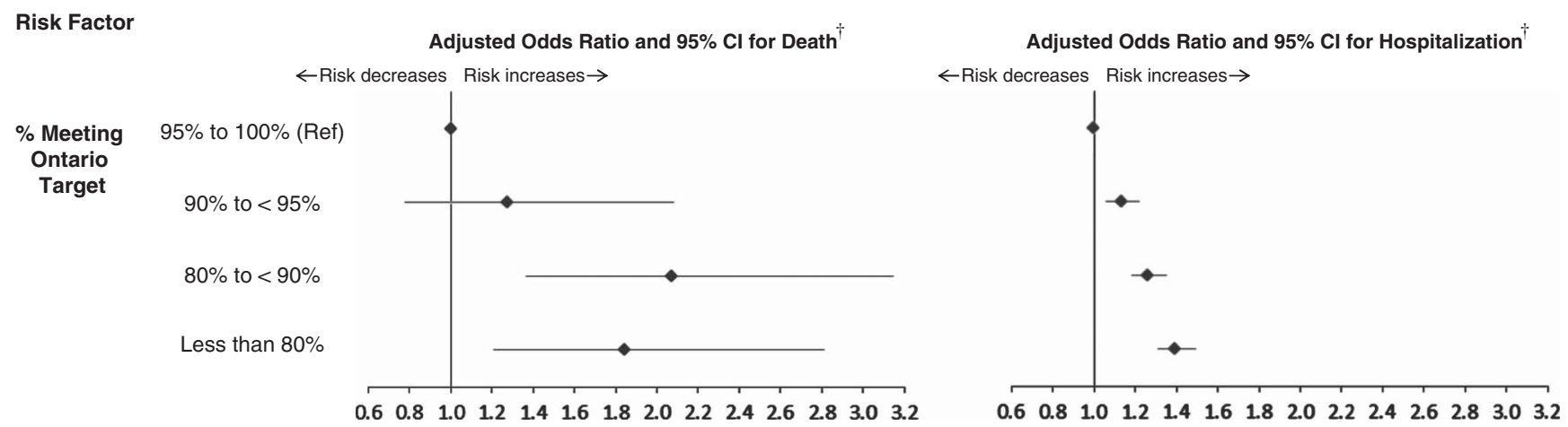

Figure 1b. Low acuity* emergency department patients' adjusted odds ratios (95\% confidence intervals) for death and hospitalization within 7 days of a visit among all non-admitted patients (seen-and-discharged and left-without-being-seen). * Canadian Triage and Acuity Scale levels 4 to 5.

tadjusted for age group, sex, triage level, calendar month, time of day, day of week, income quintile, urban/rural community, number of ED visits in the previous year, main problem.

Australia, ${ }^{16}$ Ireland, ${ }^{41}$ New Zealand, ${ }^{13}$ and several Canadian provinces, ${ }^{22,42}$ have enacted ED LOS benchmarks and targets, implemented with varying combinations of incentives and/or sanctions. Benchmarks vary widely, for example, in England (up until 2011) ${ }^{15}$ and Australia, ${ }^{16}$ the wait time benchmark has been $<4$ hours for ED patients, whereas Canadian provinces generally have different benchmarks for high-acuity patients (ranging from 4-12 hours) and low-acuity patients (ranging from $2-4$ hours). ${ }^{43}$ Jurisdictions also vary in the performance target that they set for achieving their time benchmarks, varying from $75 \%-98 \% .{ }^{15,16,43} \mathrm{In}$ the United States, some observers have suggested a similar approach, ${ }^{44}$ but the Centers for Medicare and Medicaid Services asks only hospitals to report ED LOS, whereas the Joint Commission has issued a hospital-wide patient flow standard without any benchmarks. ${ }^{45}$

\section{LIMITATIONS}

There are several limitations to this study. Administrative databases are subject to inaccuracies, but this work is focused on highly reliable data elements. ${ }^{26}$ Although there are some inaccuracies in the numbers of deaths among very young children, deaths are generally well captured among adults in Ontario in the linked databases used. ${ }^{30}$ Crowding in 8 -hour shifts was measured, which may have created bias if a patient arrived at the beginning or end of a shift. It was not feasible to examine crowding at more specific times due to ED-shift level sample size considerations. Performance ranges chosen reflected commonly used thresholds for ED LOS targets; however, these groupings may have missed important relationships at more specific performance levels. Although important 
clinical predictors were controlled, such as age, sex, triage acuity level, and chief complaint, residual confounding may exist. It is believed that it is unlikely that patient level confounders would be associated with wait time performance for other patients present in the ED on the same shift. An additional protection against residual confounding was that the analysis conditioned on the ED, thus reducing the likelihood of unmeasured confounding caused by social determinants of health. The population of ED patients is unlikely to vary substantially between crowded and less crowded shifts within the same ED. This analytic approach helped control for potential hospital confounders, such as availability of hospital resources and physician skill. Although it is possible that the physicians most likely to make optimum patient care decisions are also the ones most able to speed patient flow and hence better achieve ED LOS benchmarks, this is an unlikely alternative explanation for the results in this study, given the frequent clinician concern that excess attention to achieving wait time benchmarks might compromise patient care. ${ }^{17,46}$ The results of this work may not be generalizable to other health care systems; however, the problem of ED crowding and the organization of care within Ontario EDs are similar to many developed countries.

\section{CONCLUSION}

The aphorism “you can't manage what you don't measure" is often applied to quality improvement efforts in health care. Better management of EDs likely requires the routine measurement of ED LOS and wait times, but the experience of jurisdictions that have improved performance suggests that setting benchmarks and performance targets for ED wait times is also important to help galvanize improvement efforts. ${ }^{44}$ Results here suggest that better performance on ED wait time benchmarks is associated with substantial improvements in patient outcomes and supports current recommendations from the Canadian Association of Emergency Physicians. ${ }^{12}$ This is an important consideration for policymakers in other jurisdictions and health systems who are aiming to reduce ED crowding and improve patient outcomes.

Acknowledgments: The study was funded by the Canadian Institutes for Health Research. This study was supported by the Institute for Clinical Evaluative Sciences, a non-profit research institute funded by the Ontario Ministry of Health and LongTerm Care. The opinions, results and conclusions reported in this paper are those of the authors and are independent from the funding sources. No endorsement by Institute for Clinical Evaluative Sciences or the Ontario Ministry of Health and LongTerm Care is intended or should be inferred.

Competing interests: None declared.

\section{REFERENCES}

1. Pines JM, Localio AR, Hollander JE, et al. The impact of emergency department crowding measures on time to antibiotics for patients with community-acquired pneumonia. Ann Emerg Med 2007;50(5):510-6. doi:10.1016/j. annemergmed.2007.07.021.

2. Schull MJ, Vermeulen M, Slaughter G, et al. Emergency department crowding and thrombolysis delays in acute myocardial infarction. Ann Emerg Med 2004;44(6):577-585. doi:10.1016/j.annemergmed.2004.05.004.

3. Hwang U, Richardson LD, Sonuyi TO, Morrison RS. The effect of emergency department crowding on the management of pain in older adults with hip fracture. 7 Am Geriatr Soc 2006;54(2):270-5. doi:10.1111/j.1532-5415.2005.00587.x.

4. Pines JM, Hollander JE. Emergency department crowding is associated with poor care for patients with severe pain. Ann Emerg Med 2008;51(1):1-5. doi:10.1016/j. annemergmed.2007.07.008.

5. Guttmann A, Schull MJ, Vermeulen MJ, Stukel TA. Association between waiting times and short term mortality and hospital admission after departure from emergency department: population based cohort study from Ontario, Canada. BM7 2011;342(jun01 1):d2983-d2983. doi:10.1136/bmj.d2983.

6. Richardson DB. Increase in patient mortality at 10 days associated with emergency department overcrowding. Med $\mathcal{F}$ Aust 2006;184(5):213-6.

7. Sprivulis PC, Da Silva JA, Jacobs IG, et al. The association between hospital overcrowding and mortality among patients admitted via Western Australian emergency departments. Med 7 Aust 2006;184(5):208-12.

8. Miro O, Antonio M, Jimenez S. Decreased health care quality associated with emergency department overcrowding. Eur 7 Emerg Med 1999;6:105-7.

9. Chalfin DB, Trzeciak S, Likourezos A, et al. Impact of delayed transfer of critically ill patients from the emergency department to the intensive care unit. Crit Care Med 2007; 35(6):1477-83. doi:10.1097/01.CCM.0000266585.74905.5 A.

10. Pines JM, Hilton JA, Weber EJ, et al. International perspectives on emergency department crowding. Acad Emerg Med 2011;18(12):1358-70. doi:10.1111/j.1553-2712.2011.01235.x.

11. Medicare. Emergency department throughput measures. 2013. Available at: http://www.medicare.gov/hospitalcompare/ (X(1)S(efcfimz1hv0glomky5evj3hz))/data/emergency-waittimes.aspx?AspxAutoDetectCookieSupport=1 (accessed July 3, 2013).

12. Affleck A, Parks P, Drummond A, et al. Emergency department overcrowding and access block. CFEM 2013;15 (6):359-70; Available at: http://www.ncbi.nlm.nih.gov/ pubmed/24176460 (accessed November 25, 2013). 
13. Jones $\mathrm{P}$, Chalmers L, Wells $\mathrm{S}$, et al. Implementing performance improvement in New Zealand emergency departments: the six hour time target policy national research project protocol. BMC Health Serv Res 2012;12(1):45. doi: $10.1186 / 1472-6963-12-45$.

14. Ovens H. ED overcrowding: the Ontario approach. Acad Emerg Med 2011;18(12):1242-5. doi:10.1111/j.1553-2712. 2011.01220.x.

15. Alberti SG. Transforming emergency care in England. London, UK: UK Department of Health; 2004. Available at: http://aace.org.uk/wp-content/uploads/2011/11/TransformingEmergency-Care-in-England.pdf (accessed January 29, 2015).

16. Rudd K. New national four hour target for hospital emergency departments. Australian Government, Department of the Prime Minister and Cabinet, PM Transcripts; 2010. Available at: http://pmtranscripts.dpmc.gov.au/browse.php? $\operatorname{did}=17189$ (accessed January 29, 2015).

17. British Medical Association. BMA survey of $A$ \& $E$ waiting times. Health Policy and Economic Unit, British Medical Association. BMA House. London, UK; 2005. Available at: http://www.collemergencymed.ac.uk/code/document.asp? $\mathrm{ID}=3156$ (accessed January 29, 2015).

18. HHS, Office of the Assistant Secretary Preparedness and Response (ASPR). Healthcare Preparedness Capabilities: National Guidance for Healthcare System Preparedness. Washington, DC: HHS; 2012. Available at: http://www. phe.gov/Preparedness/planning/hpp/reports/Documents/ capabilities.pdf (accessed January 29, 2015).

19. Salkeld E, Leaver CA, Guttmann A, et al. Barriers and facilitators to the implementation of Ontario's emergency department clinical decision unit pilot program: a qualitative study. CFEM 2011;13(6):363-71; doi:10.2310/ 8000.2011.110380.

20. Bullard MJ, Unger B, Spence J, Grafstein E. CTAS National Working Group. Revisions to the Canadian Emergency Department Triage and Acuity Scale (CTAS) adult guidelines. CFEM 2008;10(2):136-51.

21. Bell R, Willett J, Oliver J. Improving access to emergency care: addressing system issues improving access to emergency care: addressing system issues. Toronto: Ontario Hospital Association, Ontario Medical Association, Ontario Ministry of Health and Long-Term Care; 2006.

22. Ontario Ministry of Health and Long-Term Care. Ontario targets shorter ER times. 2009. Available at: http://news. ontario.ca/mohltc/en/2009/02/ontario-targets-shorter-er-times. html (accessed July 4, 2013).

23. Woodcock T, Poots AJ, Bell D. The impact of changing the $4 \mathrm{~h}$ emergency access standard on patient waiting times in emergency departments in England. Emerg Med 7 2013; 30(3):e22. doi:10.1136/emermed-2012-201175.

24. Plewes L. Accident and emergency clinical quality indicators standard specification. London; 2013. Available at: http://www.isb. nhs.uk/documents/isb-1588/amd-11-2012/1588112012spec. pdf

25. Forster A, Rose N, van Walraven C, Stiell I. Adverse events following an emergency department visit. Qual Saf Health Care 2007;16:17-22.

26. Canadian Institute of Health Information. Data Quality Study of Emergency Department Visits for 2004-2005: Volume II of IV-Main Study Findings. Ottawa; 2008.
27. Canadian Institute for Health Information. CIHI Data Quality Study of Ontario Emergency Department Visits for 2004-2005: Volume II of IV-Main Study Findings. Ottawa; 2008.

28. Canadian Institute for Health Information. National Ambulatory Care Reporting System Manual for 2011-2012. Ottawa, 2011.

29. Canadian Institute for Health Information. Discharge Abstract Database Abstracting Manual, 2011-2012 Edition. Ottawa; 2011.

30. Iron K, Zagorski BM, Sykora K, Manuel DG. Living and dying in Ontario: an opportunity for improved bealth information. Toronto; 2008. Available at: http://www.ices.on.ca/file/ Living_and_dying_in_Ontario_March19-08.pdf

31. Canadian Institute for Health Information. Data Quality Documentation, Discharge Abstract Database-Current-Year Information, 2011-2012. Ottawa, 2011, Available at: http://www.cihi.ca/ CIHI-ext-portal/pdf/internet/DAD_EXECUTIVE_SUM_11_ 12_EN

32. Canadian Institute for Health Information. Data Quality Documentation for External Users: National Ambulatory Care Reporting System, 2010-2011. Ottawa; 2011, Available at: http://www.cihi.ca/cihi-ext-portal/pdf/internet/nacrs_exec_ summ_2010_2011_en

33. Berlin J, Kimmel S, Ten Have T, Sammel M. An empirical comparison of several clustered data approaches under confounding due to cluster effects in the analysis of complications of coronary angioplasty. Biometrics 1999;55: 470-476.

34. Pines JM, Hollander JE, Localio AR, Metlay JP. The association between emergency department crowding and hospital performance on antibiotic timing for pneumonia and percutaneous intervention for myocardial infarction. Acad Emerg Med 2006;13(8):873-8. doi:10.1197/j.aem. 2006.03.568.

35. Kennebeck SS, Timm NL, Kurowski EM, et al. The association of emergency department crowding and time to antibiotics in febrile neonates. Acad Emerg Med 2011; 18(12):1380-5. doi:10.1111/j.1553-2712.2011.01221.x.

36. Chatterjee P, Cucchiara BL, Lazarciuc N, et al. Emergency department crowding and time to care in patients with acute stroke. Stroke 2011;42(4):1074-80. doi:10.1161/ STROKEAHA.110.586610.

37. Pines JM, Prabhu A, Hilton JA, et al. The effect of emergency department crowding on length of stay and medication treatment times in discharged patients with acute asthma. Acad Emerg Med 2010;17(8):834-9. doi:10.1111/j.1553-2712.2010.00780.x.

38. Hwang U, Richardson L, Livote E, et al. Emergency department crowding and decreased quality of pain care. Acad Emerg Med 2008;15(12):1248-55. doi:10.1111/j.15532712.2008.00267.x.

39. Mills AM, Shofer FS, Chen EH, et al. The association between emergency department crowding and analgesia administration in acute abdominal pain patients. Acad Emerg Med 2009;16(7):603-8. doi:10.1111/j.1553-2712. 2009.00441.x.

40. Michelson KA, Monuteaux MC, Stack AM, Bachur RG. Pediatric emergency department crowding is associated with a lower likelihood of hospital admission. Acad Emerg Med 2012;19(7): 816-20. 
41. Department of Health. Special Delivery Unit Irish Department of Health. 2011. Available at: http://www.dohc. ie/about_us/divisions/special_delivery_unit (accessed July $15,2013)$.

42. Cryderman K. Health minister says Alberta won't meet emergency room wait time targets. Calgary Herald. February 2012.

43. Technical Backgrounder for the Wait Time Alliance Report Card - June 2012. The Wait Time Alliance. Ottawa, Ontario, Canada; 2012. Available at: http://www.waittimealliance.ca/
wp-content/uploads/2014/05/2012_Technical_Backgrounder. pdf (accessed January 29, 2015).

44. Rabin E, Kocher K, McClelland M, et al. Solutions to emergency department "boarding" and crowding are underused and may need to be legislated. Health Aff 2012; 31(8):1757-66.

45. The Joint Commission. The Joint Commission's new patient flow standards. Urgent Matters E-newsletter 2012;9(3):1-5.

46. Gubb J. Have targets done more harm than good in the English NHS? Yes. BM7 2009;338:a3130. 